\title{
Corrigendum: Characterizing the Intra-Vineyard Variation of Soil Bacterial and Fungal Communities
}

\section{OPEN ACCESS}

Approved by:

Frontiers Editorial Office, Frontiers Media SA, Switzerland

${ }^{*}$ Correspondence:

Lixin LUO

btlxluo@scut.edu.cn

†These authors have contributed equally to this work

Specialty section:

This article was submitted to Terrestrial Microbiology,

a section of the journal

Frontiers in Microbiology

Received: 18 June 2019 Accepted: 20 June 2019

Published: 03 July 2019

Citation:

Liang $H$, Wang $X$, Yan J and Luo L (2019) Corrigendum: Characterizing the Intra-Vineyard Variation of Soil Bacterial and Fungal Communities. Front. Microbiol. 10:1551. doi: 10.3389/fmich.2019.01551

\author{
Hebin Liang ${ }^{1+}$, Xiaowen Wang ${ }^{2,3+}$, Junwei Yan ${ }^{1}$ and Lixin Luo ${ }^{1 *}$ \\ ${ }^{1}$ School of Biology and Biological Engineering, South China University of Technology, Guangzhou, China, ${ }^{2}$ Food Testing \\ Institute, Shenzhen Academy of Metrology and Quality Inspection, Shenzhen, China, ${ }^{3}$ National Nutrition Food Testing Center, \\ Shenzhen, China
}

Keywords: vineyard soil, soil characteristics, intra-vineyard scale, bacterial community, fungal community

\section{A Corrigendum on}

Characterizing the Intra-Vineyard Variation of Soil Bacterial and Fungal Communities by Liang, H., Wang, X., Yan, J., and Luo, L. (2019). Front. Microbiol. 10:1239. doi: 10.3389/fmicb.2019.01239

In the published article, there was an error. The accession numbers for the raw data, deposited in the NCBI Short Read Archive database, are incorrect.

A correction has been made to the Materials and Methods section, subsection Accession Numbers:

"Raw data in this study have been deposited in the NCBI Short Read Archive database under accession number SRP075187".

The authors apologize for this error and state that this does not change the scientific conclusions of the article in any way.

Copyright () 2019 Liang, Wang, Yan and Luo. This is an open-access article distributed under the terms of the Creative Commons Attribution License (CC BY). The use, distribution or reproduction in other forums is permitted, provided the original author(s) and the copyright owner(s) are credited and that the original publication in this journal is cited, in accordance with accepted academic practice. No use, distribution or reproduction is permitted which does not comply with these terms. 